\title{
Meaning in Life and the Metaphysics of Value
}

\author{
Daan Evers
}

According to subjectivist views about a meaningful life, one's life is meaningful in virtue of desire satisfaction or feelings of fulfilment. Standard counterexamples consist of satisfaction found through trivial or immoral tasks. In response to such examples, many philosophers require that the tasks one is devoted to are objectively valuable, or have objectively valuable consequences. I argue that the counterexamples to subjectivism do not require objective value for meaning in life. I also consider other reasons for thinking that meaning in life requires objective value and raise doubts about their strength. Finally, I argue that beauty is not plausibly objective, but that it seems important for meaning. This puts pressure on the objectivist to explain why objectivity matters in the case of other values.

\section{Introduction}

Many philosophers think that meaning in life requires the existence of objective values. ${ }^{1}$ This paper assesses arguments for that claim. It is organized as follows: in section 2, I demarcate what most philosophers mean by a 'meaningful' life. In section 3, I explain what I mean by 'objective' value, which I think captures the intentions of most philosophers. In section 4, I show why counterexamples to subjectivism about meaning do not warrant a requirement of objective value in the sense defined. In section 5, I discuss a consideration related to the evaluation of other people's claims about meaningfulness. In section 6, I discuss some reasons for a requirement of objectivity developed by Susan Wolf. In section 7, I argue that beauty is subjective, so that those objectivists who believe that beauty can confer meaning onto life face a challenge: to explain why some values but not others have to be objective. I conclude that there are no very strong arguments for the claim that meaningfulness requires objective value.

${ }^{1}$ E.g. Susan Wolf, Meaning in Life and Why it Matters (Princeton: Princeton University Press, 2010); Thaddeus Metz, Meaning in Life (Oxford: Oxford University Press, 2013); Aaron Smuts, 'The Good Cause Account of the Meaning of Life', The Southern Journal of Philosophy 51:4 (2013), pp. 536-562. 


\section{What are Questions about the Meaning of Life about?}

One common complaint about the concept of meaning is that it is unclear. This complaint seems fair to me, but I'll do my best to clarify. Some people object that meaning is a property of sentences or utterances only. This objection presupposes that the concept of meaning as it occurs in thought about life is something like conceptual or representational content. But that is not the case. Most contemporary philosophers assume that life can be meaningful even if there is no God. So the notion of meaning at play is not something like the purpose for which humankind or particular human beings were created. These philosophers appear to have in mind a certain value that a life can have, whether or not there is a God.

The fact that meaning is a value is explicitly stated by Berit Brogaard andBarry Smith: 'Meaningfulness is ... a special kind of value which a human life can bear. More specifically, it is a kind of final value - something that we value for its own sake.'2 Thaddeus Metz concurs: '[Meaningfulness] is a gradient final good that can be exhibited by an individual's life. ${ }^{3}$ The value of meaning is supposed to be at least conceptually distinct from that of moral worth, well-being and happiness. Its distinctiveness is often motivated by examples: Van Gogh's life is said to have been meaningful even if it was low in happiness. Those inclined to make that judgement appear to make it without particular attention to the painter's moral qualities, which might be thought to illustrate the fact that meaning is distinct from moral worth. ${ }^{4}$

It is much harder to show that meaning is distinct from well-being without taking a controversial stand on either issue. There are views of well-being according to which it is a matter of satisfying a list of goods, the contribution of which to one's wellbeing is independent of how they make you feel or whether they fulfill your desires. And there are views about meaning that coincide with desire satisfaction views of well-being.

Some philosophers say that a meaningful life is one towards which certain attitudes are appropriate, like admiration or pride, feelings of satisfaction, elevation and inspiration. ${ }^{5}$ Perhaps the appropriateness of some of these could help to distinguish the notion of well-being from that of meaningfulness. In so far as the concept of well-being is equally applicable to animals, one might say that it should not entail that admiration or pride or elevation are appropriate. The life of a mouse may be high in well-being but not an appropriate object of esteem or inspiration. ${ }^{6}$

\footnotetext{
2 Berit Brogaard and Barry Smith, 'On Luck, Responsibility and the Meaning of Life', Philosophical Papers 34:3 (2005), pp. 443-458, at p. 443.

${ }_{3}^{3}$ Metz, Meaning in Life, p. 60.

4 Although it may be that we (often) assume that meaningful lives meet at least a threshold of moral decency.

${ }^{5}$ E.g. Anti Kauppinen, 'Meaningfulness and Time', Philosophy and Phenomenological Research 84:2 (2012), pp. 345-377 and Metz, Meaning in Life.

${ }^{6}$ Even this is not obvious since the appropriateness of attitudes like pride and esteem may be relative to abilities. If a mouse's well-being is partly the result of good exercise of the mouse's abilities, we may want to say that it would be appropriate for the mouse to feel pride, or for others to admire the mouse, even if a mouse is not capable of that attitude (I owe this suggestion to Frans Svensson). The question remains whether a response along these lines is plausible for all attitudes that one may think are conceptually connected to the concept of meaningfulness.
} 
For my purposes, it does not matter too much whether we can clearly distinguish meaning from well-being. I am interested in the question whether we have strong reason to think that it requires the existence of objective value.

\section{Subjectivism about Value}

Since my aim is to assess arguments for the claim that a meaningful life requires objective value, it is important to be clear on objectivity. Subjectivists about value in my sense are either expressivists, or believe that the instantiation of values is determined by (relations to) contingent standards or responses of individuals under either actual or idealized conditions. ${ }^{7}$ Objectivists deny this.

An example of subjectivism in my sense is the position known as simple subjectivism, according to which ' $X$ is wrong' means that the speaker disapproves of $X$. This view entails that $X^{\prime}$ 's being wrong consists in its being disapproved of by the speaker. In my stipulative use, a non-expressivist view only counts as subjectivist if it takes value either to be constituted by or metaphysically dependent on the responses of individuals. ${ }^{8}$ I rule out ideal observer theories that require convergence in response between suitably idealized judges. Subjectivism, in my sense, includes at least expressivism, ${ }^{9}$ contextualism, ${ }^{10}$ Humean constructivism, ${ }^{11}$ and truth-relativism. ${ }^{12}$

It is clear that at least some philosophers in the debate believe that meaning requires objective value in a sense which goes beyond the positions just described. For instance, Aaron Smuts says that his view involves 'strong commitments to value realism', ${ }^{13}$ a term not usually applied to expressivist or contextualist views. Thaddeus

\footnotetext{
7 So long as those idealized conditions do not themselves involve the perception or instantiation of standard- or response-independent facts about value.

8 By 'metaphysical dependence' I mean that the instantiation of value properties is a function of contingent standards or responses of a judge under either actual or hypothetical conditions. This addition is required in order to cover relativist views à la John MacFarlane, Assessment Sensitivity. Relative Truth and Its Applications (Oxford: Oxford University Press, 2014). According to MacFarlane, (certain) propositions about value are true or false relative to the standards or responses of assessors, even if those propositions are not about standards or responses. In that case, it is natural to think that value is not itself constituted by (relations to) standards or responses, even if its instantiation is. For more on issues relating to this, see Daan Evers, 'Relativism and the Metaphysics of Value', unpublished.

9 For examples of expressivism about moral language, see Simon Blackburn, Ruling Passions (Oxford: Clarendon Press, 1998) and Allan Gibbard, Thinking How to Live (Cambridge, MA: Harvard University Press, 2003).

10 For an example of contextualism about value discourse quite generally, see Stephen Finlay, Confusion of Tongues. A Theory of Normative Language (Oxford: Oxford University Press, 2014).

11 For an example of constructivism about reasons for action see Sharon Street, 'Constructivism about Reasons', in Oxford Studies in Metaethics vol. 3, edited by Russ Shafer-Landau (Oxford: Clarendon Press, 2008), pp. 207-245 (although Street's Humean constructivism is clearly a form of contextualism).

12 For an example of truth-relativism about predicates of personal taste and other domains, see MacFarlane, Assessment Sensitivity.

13 Smuts, 'The Good Cause Account of the Meaning of Life', p. 27.
} 
Metz requires objectivity in a sense strong enough to entail that what is morally and aesthetically valuable is necessarily the same for all members of the human race. ${ }^{14}$ Although Susan Wolf is harder to pin down, her discussion in Meaning in Life and Why it Matters makes clear that the objectivity of value goes beyond what an individual happens to care about, even under ideal conditions. My aim in this paper is to see whether we have any strong reason to accept that meaning in life requires the existence of values that are not subjective in my stipulative sense.

\section{Counterexamples to Subjectivism about Meaning}

Subjectivism about meaning in life can come in various guises, but they all share the idea that a life is meaningful in virtue of nothing more than that the subject takes some positive attitude (such as desire or feelings of fulfilment) towards the dominant activities or events in her life. ${ }^{15}$ This is a substantive position in the debate about meaning, not to be confused with subjectivism about value in the sense defined in section 3 . The subjectivist about meaning provides a standard for ascribing meaning to a person's life: it is meaningful insofar as it satisfies the agent's desires or pro-attitudes. The subjectivist about value advances semantic or metaphysical claims: either judgements of value are non-cognitive states, or values are constituted by (relations to) the standards or responses of individuals, or the instantiation of value depends on such standards or responses.

Some philosophers motivate their subjectivist criterion for meaning at least in part by metaphysical considerations. For example, Harry Frankfurt recommends his subjectivist view in part by drawing attention to the fact that 'efforts to make sense of "objective value" tend to turn out badly'. ${ }^{16}$ Subjectivist Steven Luper comments on what he calls 'externalism' by saying that it is 'difficult to defend' ${ }^{17}$ I take his point to be that objective (or external) facts about value are difficult to defend. But why should that support his own substantive view about meaning?

If Brogaard, Smith and Metz are right that meaning is a value, then one would expect the question what makes a life meaningful to be the same sort of question as the normative question what makes an action right or wrong, or a person good or bad. Such questions are normally debated without much concern for metaethics. I am not aware of anyone who takes the non-existence of objective moral facts to be a reason to embrace a subjectivist normative view, according to which what makes an action right is its conduciveness to the satisfaction of the agent's desires. ${ }^{18}$ J.J.C. Smart happily combined

\footnotetext{
14 Metz, Meaning in Life, chapter 5.

15 E.g. Richard Taylor, 'The Meaning of Life', in The Meaning of Life: A Reader, $3^{\text {rd }}$ edition, edited by Elmer Klemke, and Stephen Cahn (New York: Oxford University Press, 2009), pp. 13-14; Harry Frankfurt, 'Reply to Susan Wolf', in Contours of Agency: Essays on Themes from Harry Frankfurt, edited by Sarah Buss, and Lee Overton (Cambridge, MA: MIT Press, Bradford Books, 2002), pp. 245-252; Steven Luper, 'Life's Meaning', in The Cambridge Companion to Life and Death, edited by Steven Luper (Cambridge: Cambridge University Press, 2014), pp. 198-214.

16 Frankfurt, 'Reply to Susan Wolf', p. 250.

17 Luper, 'Life's Meaning', p. 210.

18 A reviewer for this journal suggests that the reason why no one makes this move in ethics might be that ethics is concerned with the interests of others, whereas a meaningful life seems more
} 
his expressivist view of moral language with a first-order utilitarian moral view. ${ }^{19}$ And Bernard Williams saw no tension between his acceptance of a non-consequentialist ethics, and his relativism about value. ${ }^{20}$

Once substantive and metaphysical questions are clearly distinguished, it also emerges that standard counterexamples to subjectivism do not require a move to objectivism about value. Yet some philosophers appear to think they do.

As indicated, subjectivism about meaning in life is the idea that a life is meaningful in virtue of nothing more than that the subject takes some positive attitude towards the dominant activities or events in her life. The most common reason for rejecting all versions of subjectivism is that they would entail that apparently meaningless lives are in fact highly meaningful. Metz gives a list of examples offered in the literature:

Not only would [subjectivism] entail that Sisyphus's life could be meaningful merely for having fulfilled a desire to roll a stone, it would also entail that a person's existence could become significant by merely: staying alive; harming others; growing more corn to feed more hogs to buy more land to grow more corn to feed more hogs to buy more land to grow more corn, and so on ad infinitum; orienting her life around a single colour; maintaining 3,732 hairs on her head; engaging in conspicuous consumption and being self-absorbed; collecting bottle tops; memorizing the dictionary, or recounting the numbers of tiles on the bathroom floor; watching reruns of television series such as Buffy, The Vampire Slayer; lining up balls of torn newspaper in neat rows; trying to make flowers sing or becoming addicted to drugs; or (best of all!) ingesting her own excrements. ${ }^{21}$

Examples like these have recently convinced a number of philosophers that a life cannot be meaningful merely because the subject desires to be engaged in her activities, or feels fulfilled by them. ${ }^{22}$ But it is important to realize that this substantive conclusion does not support the claim that a meaningful life involves engagement with objective value. The counterexamples to subjectivism suggest that meaningful lives are devoted to certain activities rather than others. They do not suggest that the value of these activities has a certain metaphysical status.

closely connected to the interests of the agent. But even if that were so, it does not make the move from the non-existence of objective value to subjectivism about meaning any more acceptable. The thesis that meaningfulness is tied to individual interests might justify the move to some extent, but why should the rejection of objective facts about value license it?

19 John Smart and Bernard Williams, Utilitarianism: For and Against (Cambridge: Cambridge University Press, 1973).

20 See e.g. Smart and Williams, Utilitarianism: For and Against; Bernard Williams, 'Internal and External Reasons', in Moral Luck. Philosophical Papers 1973-1980 (Cambridge: Cambridge University Press, 1981), pp. 101-113.

${ }^{21}$ Metz, Meaning in Life, p. 175. I have modified the quote by leaving out the references to the sources of the examples.

22 E.g. Wolf, Meaning in Life and Why it Matters; Kauppinen, 'Meaningfulness and Time'; Metz, Meaning in Life; Smuts, 'The Good Cause Account of the Meaning of Life'; Ben Bramble, 'Consequentialism about Meaning in Life', Utilitas 27:4 (2015), pp. 445-459. 
The foregoing is not always firmly held in view. For instance, Aaron Smuts offers counterexamples to subjectivism about meaning, and proposes a consequentialist view according to which the sole requirement is that the world is better off because of one's existence. ${ }^{23}$ He then states that his view involves 'strong meta-ethical commitments to value realism'. ${ }^{24}$ But why should that follow from the rejection of subjectivism, or the acceptance of consequentialism? If consequentialism is compatible with expressivism or relativism in the case of ethics, why should it not be in the case of meaning?

Clearly, then, one can in principle divorce meta-normative questions about the status of value from substantive questions about the conditions under which a life would count as meaningful. It may be true that our standards require more of a meaningful life than that the subject feels fulfilled, but that does not require objective truths about which standards are correct. At least the following combination of views seems perfectly intelligible: (1) Metz's view that meaning is a matter of orienting one's rationality towards fundamental conditions of human existence and (2) the meta-normative view that the status as a value of orienting one's rationality towards such conditions is a matter of me (the speaker) holding this kind of standard for a meaningful life. Similarly, there appears to be no tension between (1) Smuts's view according to which a life is meaningful in virtue of the production of valuable consequences and (2) a subjectivist metaphysics of value. Such a combination of views would be exactly analogous to Smart's combination of utilitarianism with expressivism, or Williams's combination of a non-consequentialist ethics with a form of relativism.

The possibility of combining a non-subjectivist criterion for a meaningful life with a subjectivist metaphysics of value should be a welcome result for those philosophers who feel ambivalent about the existence of objective value, yet cannot accept that all there is to meaning is fulfilment of the agent's pro-attitudes..$^{25}$

\section{The Argument from Truth Evaluation}

I've argued that counterexamples to subjectivism do not justify a requirement of objective value on a meaningful life. But there may be other reasons for such a requirement. One reason is a meta-normative consideration analogous to moves made in debates in metaethics. It goes as follows: if we embraced subjectivism about the value that meaningfulness is, we would have to allow that the judgement 'Sisyphus's life is meaningful' is true or correct when made by someone who values that life highly. But we think that it is false. Therefore, a life's being meaningful cannot be a matter of corresponding to the values of the judge. Call this the problem of truth evaluation.

This argument presupposes that if meaningfulness were a matter of subjective value, then a certain contextualist theory would be true. The relevant theory holds that the truth condition of a statement like

23 Smuts, 'The Good Cause Account of the Meaning of Life'.

24 Ibid., p. 27.

25 For another defence of the compatibility of expressivism, or rather quasi-realism, with meaningful lives, see Mark Rowlands, 'The Immortal, the Intrinsic, and the Quasi Meaning of Life', The Journal of Ethics 19:3/4 (2015), pp. 379-408. 
(1) Sisyphus's life is meaningful

involves the standards for meaningfulness held by the speaker. If the speaker's standards rank Sisyphus's life sufficiently highly, then contextualism of this variety predicts that (1) is true, and the fact that we are not inclined to call it true is a problem for the theory.

There are two ways of responding. One is to offer contextualism-friendly explanations of our reluctance to call (1) true. For moral discourse, such explanations are attempted by Stephen Finlay and for judgements of personal taste and epistemic modals by Gunnar Björnsson and Alexander Almér. Finlay suggests (among other things) that our tendency to assess the truth of moral claims from our own perspective is explained by the assumption that others share our standards at least in relevant respects. ${ }^{26} \mathrm{Björnsson}$ and Almér offer a complex, yet plausible explanation of the insensitivity of assessments of judgements of personal taste to the responses of the speaker. ${ }^{27}$ I will sketch the most important aspect of their view.

Björnsson and Almér note that the naturalness of in sensitive assessments in various domains depends on what is of interest or at stake in the conversation, which need not always be the truth conditions of the proposition uttered by the speaker. Take the following exchange:

(2) A: I wonder if the keys are in the car.

(3) B: No, Beth has them in her pocket. ${ }^{28}$

Clearly, (3) is not the negation of the proposition expressed by A in (2). Its naturalness is explained by the fact that what is at stake is the location of the keys. Björnsson and Almér suggest that a similar mechanism could explain the naturalness of exchanges like the following:

(4) A: These fish sticks are delicious!

(5) B: No, they are disgusting.

(5) might be natural as a response to (4) for similar reasons as (3) is a natural response to (2), even if the proposition expressed by A's utterance in (4) is really about the relation of fish sticks to A's standards, or has truth conditions involving those standards: of interest in this conversation is a comparison of taste, not the truth value of the proposition uttered by A.

When we apply this to discourse about meaningful lives, we can explain why we may not be inclined to call (1) true, even if its truth conditions involve the standards for

26 Stephen Finlay, 'The Error in the Error Theory', Australasian Journal of Philosophy 86:3 (2008), pp. 347-369.

27 Gunnar Björnsson and Alexander Almér, 'The Pragmatics of Insensitive Assessments. Understanding the Relativity of Assessments of Personal Taste, Epistemic Modals, and More', The Baltic International Yearbook of Cognition, Logic and Communication 6 (2011), pp. 1-45.

28 The example is from Björnsson and Almer, 'The Pragmatics of Insensitive Assessments. Understanding the Relativity of Assessments of Personal Taste, Epistemic Modals, and More', p. 22. 
meaningful lives held by the speaker: what is at stake in the conversation is a comparison of values.

Even if the foregoing fails, there is a more powerful response to the problem of truth evaluation. It is that a subjectivist metaphysics of value does not entail (this or any kind of) contextualism about the semantics of value discourse in the first place. Perhaps discourse about value is expressive, as opposed to descriptive, of our standards. ${ }^{29}$ Or perhaps a sophisticated kind of relativism works, such as John MacFarlane's. ${ }^{30}$ According to MacFarlane's relativism, the truth of statements about value depends on the standards of an assessor of the proposition expressed, even though such propositions are not about anyone's standards (including the standards of the speaker). Expressivism and MacFarlane-style relativism both predict that we would reject Sisyphus's life as meaningful - and assess (1) as false - even though there are no objective facts about value.

So the argument that subjectivism about value entails that apparently false statements are in fact true does not support the view that meaning requires objective value. For (1), subjectivism does not entail that in the first place, and (2), there may be explanations of our reluctance to consider such statements true that do not involve commitments to objective value.

\section{Wolf's Endoxa}

Susan Wolf uses what she calls the 'endoxic method' to defend her hybrid view about meaning in life. ${ }^{31}$ This method is essentially that of synthesizing the various elements involved in thought about meaning. ${ }^{32}$ Wolf believes that two important strands are, first, that finding meaning in life is a matter of finding something you care about, or love, yourself, as opposed to something that's merely expected or required by others. Subjectivists give pride of place to this consideration (sometimes called "the passion requirement"). A second important strand is the idea that a meaningful life requires involvement with something "larger than oneself". ${ }^{33}$ The idea here is that a meaningful life is not just a matter of doing things you like or that are good for you, but also something that is valuable from a more objective standpoint:

When we consider what deep human interests or needs a meaningful life distinctively answers to ... the objective aspect of such a life needs to be stressed. Our interest in living a meaningful life is not an interest in a life feeling a certain way; it is an interest that it be a certain way, specifically, that it be one that can be appropriately

29 Blackburn, Ruling Passions; Gibbard, Thinking How to Live; Michael Ridge, Impassioned Belief (Oxford: Oxford University Press, 2014).

30 MacFarlane, Assessment Sensitivity. Relative Truth and Its Applications.

31 Wolf, Meaning in Life and Why it Matters.

32 Though not in a sense which requires that whatever is commonly thought about meaning is infallible. The "endoxa" are starting points for thinking about meaning, or desiderata that matter for an assessment of a view. What this means, I think, is that the endoxic method is that of seeking reflective equilibrium.

33 Wolf, Meaning in Life and Why it Matters, p. 18. 
appreciated, admired, or valued by others, that it be a life that contributes to or realizes or connects in some positive way with independent value. 34

Wolf thinks that longing for meaning is longing for more than subjective satisfaction. One also wants to contribute to something of more than merely personal value. The question is whether this requires objectivity in any very strong sense. Part of Wolf's view is that a life that is 'totally egocentric, devoted solely toward the subject's own survival and welfare' is not meaningful. ${ }^{35}$ This is of course compatible with a subjectivist metaphysics of non-egocentric value.

But Wolf also thinks that the desire to contribute to something larger than oneself requires metaphysical objectivity:

in order for one's activities or projects to contribute to the meaningfulness of one's life, not only must the locus or recipient of value lie partly outside of oneself, the standard of judgment for determining value must be partly independent, too. ${ }^{36}$

One of her main reasons for this claim appears to be that one can be mistaken about the meaningfulness of one's projects. First, she notices that a person can be mistaken from a third-person point of view, as when Sisyphus feels fulfilled by rolling his rock up the hill forever:

Sisyphus Fulfilled [was] meant to suggest the conceivability of a person finding an activity fulfilling that we might find inadequate for meaning from a third-person perspective. Insofar as (this version of) Sisyphus thinks his life is meaningful, he is mistaken, finding something in stone-rolling that isn't really there. ${ }^{37}$

This phenomenon is still compatible with a subjectivist metaphysics of value, as I've argued in the previous section: we can legitimately consider Sisyphus's life as meaningless, even if there are no objective values. But Wolf also notices that one's own standards can seem mistaken:

The judgment that what seemed worthwhile wasn't really so may be made by the person himself, looking back on a past phase of his existence. One might even 'wake up' more or less suddenly to the realization that an activity one has been pursuing with enthusiasm is shallow or empty. 38

Does this require objective values? Notice that one's former standards may be mistaken as considered from one's current ones. So the phenomenon can still be explained without

\footnotetext{
34 Ibid., p. 32.

35 Ibid., p. 41.

36 Ibid., p. 43. Notice that Wolf requires that the values that make one's life meaningful are objective, not (primarily) that meaningfulness is itself an objective value. But it seems strange to say that although the values on which meaning supervenes have to be objective, meaning is itself a subjective value. So Wolf is most naturally interpreted as holding the view that both meaning and the values on which meaning supervenes are objective.

37 Wolf, Meaning in Life and Why it Matters, p. 43.

38 Ibid., p. 44.
} 
appeal to objective values. But Wolf clearly thinks that this is insufficient. She believes that our desire to contribute to something larger than oneself is best understood in terms of relating to objective value.

If that is right, then it won't help to go quasi-realist, and insist that there is some interpretation of the language of objectivity as a matter of first-order normative discourse, as Blackburn does in Ruling Passions. The point is that the right metaphysical story about the nature of value should involve something over and above human tendencies to care about and value things.

Although I have no knock-down arguments against Wolf's position, the judgement that a requirement of objective value is part of the best systematization of our thought about meaning can be doubted. There are at least four sources of tension between such a requirement and aspects of our thought about meaning. Bringing these out will help to see the advantages of a view that does not require objective values. I will discuss the first three sources in this section, and the fourth one in the next.

The first source of tension is the fact that we are strongly inclined to consider some lives as meaningful, like those of Charles Darwin, Albert Einstein, Philippa Foot and Bridget Riley. Thaddeus Metz even takes some of these as paradigms of meaningfulness, part of what determines our grip on the concept of meaning itself. So there is some pressure to preserve these judgements. But if objective values were required for meaning, then there is a serious chance that all lives were in fact meaningless. Wolf herself considers various options concerning the metaphysics of objective value and finds all of them wanting. According to her, a plausible metaphysics for objective values is "an unsolved problem in philosophy". ${ }^{39}$ In my view, this problem is unsolvable because there are no objective values. But does this make us significantly inclined to say that the lives of Darwin, Einstein, Foot and Riley were meaningless?

The second source of tension is that objectivity sometimes doesn't seem to make a difference. Imagine a world inhabited by just one person. Imagine that she discovers important truths about the universe. Her discoveries are a great source of satisfaction to her, but no one else will ever learn about them. Are we supposed to think it makes a difference to the meaningfulness of her life whether acquiring knowledge is objectively valuable? That is not clear to me. I do think that her life would become more meaningful the more her discoveries were shared with others. But that doesn't tell us anything about the nature of value. One can perfectly well hold the normative view that a life is more meaningful the more one's achievements are shared with others, and combine this with a non-objectivist metaphysics of value.

The third source of tension relates to our interest in God with respect to questions about the meaning of life. One reason why God may seem important to the meaning of our lives is that people want to matter to someone, which in turn may reflect a lack of interest in values that are no one's, or matters of abstract, soulless fact. We may find it more important to matter to someone, than that our mattering is independent of perspectives. Similarly, we may care more that our activities are acknowledged as valuable by others, than that the nature of their valuableness is a matter of objective fact. 
Thomas Nagel's observations about the role of value in answering questions about the meaning of life also suggest that what matters is not primarily the status of the values we promote, but their relation to our own perspectives:

Those seeking to supply their lives with meaning usually envision a role or function in something larger than themselves. They therefore seek fulfillment in service to society, the state, the revolution, the progress of history, the advance of science, or religion and the glory of God.

But a role in some larger enterprise cannot confer significance unless that enterprise is itself significant. And its significance must come back to what we can understand, or it will not even appear to give us what we are seeking. If we learned that we were being raised to provide food for other creatures fond of human flesh, who planned to turn us into cutlets before we got too stringy - even if we learned that the human race had been developed by animal breeders precisely for this purpose - that would still not give our lives meaning, for two reasons. First, we would still be in the dark as to the significance of the lives of those other beings; second, although we might acknowledge that this culinary role would make our lives meaningful to them, it is not clear how it would make them meaningful to us. ${ }^{40}$

Nagel's observations indicate that any purpose our lives might have must be recognizable by us as valuable in order to have a chance of answering concerns about the meaning of our lives. They suggest a kind of priority that the content of our values has over their status, in the sense that if what is objectively valuable turned out to be wildly at variance with anything we might consider important, then we could not be persuaded of life's meaning.

The foregoing does not prove that the status of the values that confer meaning onto our lives does not matter as well. All that it strictly shows is that objectivity by itself is not enough, and that the content of the values matters too (they must be appropriately related to our own concerns). This is one reason why I claimed to lack knock-down arguments against a requirement of objective value.

My fourth and final reason to doubt that a requirement of objective value is clearly part of the best systematization of thought about meaning has to do with beauty. It deserves a separate section.

\section{The Subjectivity of Beauty}

Many people who think that lives can be meaningful think they can be meaningful in virtue of the creation of or engagement with beauty. But beauty is not plausibly objective, as I will argue below. If so, then at least some values that can make a life meaningful don't have to be objective. That places a burden on objectivists to explain why it should matter for others.

Something like the foregoing consideration is used by Thaddeus Metz to argue against an overly robust requirement of objectivity. ${ }^{41} \mathrm{He}$ points out that some lives

40 Thomas Nagel, 'The Absurd', The Journal of Philosophy 68:20 (1971), pp. 716-727, at pp. 720-721.

${ }^{41}$ Metz, Meaning in Life, chapter 5. 
devoted to art seem very meaningful, and beauty plays at least an important role in art. However, it is not plausible that what is beautiful or not is independent of human beings. For this reason, Metz thinks a kind of naturalism about beauty should suffice. According to the form he favours, beauty is identical to a natural property in virtue of a baptism that fixes the reference of the term for all subsequent (human) users.

Metz believes this view, often associated with Cornell realism, imbues beauty (and morality) with enough objectivity and universality to avoid a charge of arbitrariness: the charge that whether lives are meaningful is just a matter of what anyone happens to like or accept. At the same time, it does not require the existence of either supernatural or non-natural entities. Metz believes that the existence of the latter is more uncertain than that some lives were meaningful, to the point where he claims to know the latter, but not the former. Since he cannot consistently claim to know

(6) that some lives were meaningful

and

(7) that meaningfulness requires supernatural or non-natural entities,

but not to know

(8) that supernatural or non-natural entities exist,

he opts for a form of naturalism instead. Metz presumably does this because naturalists have few controversial elements in their ontology (even if it is controversial whether those elements comprise everything that exists).

However, it would be a mistake to think that uncontroversial building blocks suffice to make his claim to knowledge of (6) of comparable certainty as his naturalist theory of value. Cornell realism may itself be more uncertain than that some lives were meaningful. In fact, I think that it is false. And even if it were true, it would fail to secure the universality of beauty. A plausible, naturalism-friendly metaphysics and semantics of beauty is much more subjective than Metz allows. If so, and if we think that some lives are meaningful in virtue of the creation of beauty, we cannot be objectivists about all values that confer meaning on our lives. This is significant because it raises an explanatory challenge: why would any values have to be objective if some do not?

In what follows, I will first argue that the most plausible version of Cornell realism fails to distinguish itself from relativism. Then, I will give a reason to think that no objectivist account of beauty, including Cornell realism, could be right.

More plausible versions of Cornell realism say that the reference of value terms, like 'beautiful', is determined by a causal process: 'beautiful' refers to whatever is appropriately causally responsible for tokenings of the concept of beauty. (The reason for this is that one does not want to be stuck referring to whatever it is that cavemen dubbed 'beautiful' throughout the centuries.) Now, quite obviously, people find different things beautiful. This means that different features tend to cause their respective tokenings of the concept of beauty. In order to avoid rampant talking-past-one-another, the Cornell realist needs to identify the property of being beautiful not with whatever properties 
(tend to) cause a favourable response in the speaker, but with the dispositional property of being such as to (have a tendency to) cause a favourable response (I will leave out the qualification about the tendency henceforth). This allows the reference of 'beauty' to be the same property, even when the term is used by people with very different tastes. Both could then refer to the same property of being such as to cause a favourable response.

However, if people do have different tastes, then it is possible for two speakers to make opposing claims about the beauty of an object. Speaker 1 might say that it is beautiful, while speaker 2 might say that it is not. Furthermore, their respective judgements may be stable upon further encounters and reflection. I think it is reasonable to assume that one and the same object cannot both have the property of being such as to cause a favourable response, and simultaneously lack that very same property. What this suggests is that the first and second speaker's tokenings of their concept of beauty is causally regulated by different properties. Plausibly, speaker 1's tokenings are regulated by the property of being such as to cause a favourable response in people like speaker 1 , and speaker 2's tokenings are regulated by the property of being such as to cause a favourable response in people like speaker 2. But if so, then this non-reductive naturalist view of beauty cannot guarantee its universality. ${ }^{42}$

Of course, there is still a sense in which such a view can guarantee that beauty is universal. You might say that speaker 1 and speaker 2 are using different concepts (beauty ${ }_{1}$ and beauty2), and that it is universally and necessarily true that beauty 1 is identical to the property of being such as to cause a favourable response in people that resemble speaker 1 , and universally and necessarily true that beauty 2 is identical to the property of being such as to cause a favourable response in people that resemble speaker 2. Anyone who uses the concept of beauty $1_{1}$ would be mistaken in ascribing it to anything that isn't such as to cause a favourable response in people that resemble speaker 1.

However, this is small comfort to the Cornell realist, as it gives the view no discernible advantage over indexical contextualism. An indexical contextualist says that value claims are really claims about the relation in which objects stand to certain standards. In the case of ordinary claims about beauty, the standards are plausibly determined by dispositions of the speaker. So if speaker 1 says:

(9) Bach's music is beautiful

then she expresses the proposition that Bach's music ranks highly in relation to speaker 1's standards. If speaker 2 says:

(10) Bach's music is awful

then she expresses the proposition that Bach's music ranks lowly in relation to speaker 2 's standards. This is a form of subjectivism about beauty. However, the indexical contextualist could make the same move as I just canvassed for the Cornell realist. She could say that speaker 1 and speaker 2 are using different concepts, beauty 1 and beauty ${ }_{2}$. Anyone who uses the concept expressed by speaker 1 would be wrong to say that Bach is

42 It is not very plausible that this result can be avoided by appeal to referential intentions in speaker 2 to refer to whatever it is that speaker 1's use of the concept is regulated by. 
awful. I doubt that anyone would take this to mean that contextualism is after all a kind of objectivism about value.

You might think that Cornell realism at least allows metaphysically necessary property identities, even if many different people refer to different properties with their use of 'beautiful'. However, the indexical contextualist can appeal to even stronger forms of necessity. She can say that the property of being beautiful ${ }_{1}$ is - as matter of conceptual necessity - identical to the property of ranking highly on the standards held by people similar to speaker 1 .

So I doubt that Cornell realism fares any better with respect to beauty than indexical contextualist accounts. That by itself does not establish that there is no plausible, objectivist account of beauty available. But there is a good reason to think that no (overly) objectivist account could work.

Many aestheticians accept a principle along the following lines: one cannot sincerely call an object beautiful unless one has had a positive response to it oneself. ${ }^{43}$ I think this principle is plausible only for judgements of beauty based on an encounter with the object (as opposed to testimony), ${ }^{44}$ but even that makes trouble for objectivist theories of beauty. For suppose the word 'beauty' refers to a natural or non-natural property that is objective in the sense of not being instantiated in virtue of the production of a positive response in the speaker. That makes it very hard to see why it should be a requirement on sincere, non-testimony based judgements of beauty that the object elicits a positive response in the judge.

One might try to explain the requirement by saying that the property of being beautiful is the property of being such as to cause a favourable response in any human being, including oneself. That would give it universality, and explain why it is odd to call an object beautiful prior to having reason to believe it would produce a positive response in oneself (which we ordinarily find out by actually experiencing such a response). However, the suggestion makes it hard to see why anyone would feel comfortable making judgements about beauty without first acquiring evidence about the object's effect on other people's, and threatens to condemn all - or at least most - , judgements about beauty to falsehood. For there are very few things that all human beings necessarily find beautiful.

So, objectivist accounts have a hard time explaining the sincerity condition on statements about beauty. What this suggests is that the most plausible accounts of beauty are subjectivist. If a meaningful life really did require engagement with objective values, then we should have a strong tendency to consider lives devoted to art as meaningless. But I don't think that we have that in the slightest.

If one did want to hold on to the need for objective values, the best route would be to push the idea that even though what is beautiful and ugly is subjective, it is

43 This principle derives from Immanuel Kant, Critique of Judgement, translated by James Meredith (Oxford: Clarendon Press, 1951), §33. It is sometimes referred to as the principle of the autonomy of aesthetic judgement (e.g. Cain Todd, 'Quasi-Realism, Acquaintance, and the Normative Claims of Aesthetic Judgement', British Journal of Aesthetics 44:3 (2004), pp. 277-296, at p. 278). The principle of autonomy should not be confused with the Acquaintance Principle, critically discussed by Malcom Budd, 'The Acquaintance Principle', British Journal of Aesthetics 43:4 (2003), pp. 386-392.

${ }^{44}$ An encounter can be either direct or mediated by a reproduction. 
objectively valuable to produce experiences of beauty. That would be like saying that although what is pleasant and unpleasant is subjective, it is objectively valuable to produce pleasant experiences. But this has problematic implications. It would make it hard to justify according more meaning to the life of someone who devotes their life to promoting Bach than to the life of someone who devotes their life to promoting James Last. The latter life may, after all, induce a lot more experiences of beauty. Notice that such differential rankings are unproblematic once you separate normative questions about what makes a life meaningful from metaphysical questions about the status of value: one can simply hold a standard that ranks Bach more highly, even if the quality or beauty of his music is ultimately a matter of subjective fact.

\section{Conclusion}

Many philosophers think that subjectivism about meaning in life is false. According to this view, a life is meaningful (roughly) in virtue of satisfying the subject's desires. The most common objection against it is the implication that lives devoted to trivial or immoral tasks can be highly meaningful. Some philosophers conclude that a meaningful life requires objective value: value that exists independently of contingent concerns of human beings, and should not be understood along expressivist lines. I have argued that this is a mistake: one can coherently accept both that lives are meaningful in virtue of more than desire satisfaction and that value is metaphysically subjective. Coherence is maintained so long as one considers the question what constitutes a meaningful life as a normative question, and the question about the nature of value as a metanormative concern.

I have considered two reasons for thinking that meaningfulness requires objective value after all: one is that we don't assess other people's statements about what constitutes a meaningful life as true so long as they conform to the standards of those people. I've argued that metaphysically subjectivist accounts of value need not predict this behaviour in the first place, or may explain it satisfactorily. The other reason was Wolf's claim that part of the content of our desire for meaning is to contribute to something larger than oneself. Wolf thinks this is best interpreted as a desire to contribute to something of objective value. I have argued that there are at least four reasons to be sceptical of this: (1) our judgements that some lives were meaningful may survive the discovery that objective values don't exist. (2) We don't always seem to think that the objectivity of value enhances the meaning of imaginary lives. (3) Even objective values cannot answer questions about meaning unless they resonate with us. (4) Part of the paradigms of meaningful lives are lives devoted to beauty, but the best metaphysics of beauty is probably subjectivist. If some subjective values can confer meaning onto people's lives, then why would others have to be objective?

If it is more plausible that some lives are meaningful than that objective values exist, it is best to see the debate about meaningfulness as a normative issue. For that allows us to be neutral about the nature of value. However, even a subjectivist 
metaphysics of value does not force us to be subjectivists about the meaning of life. I hope to have shown at least this. ${ }^{45}$

\section{Bibliography}

Björnsson, Gunnar, and Alexander Almér. 'The Pragmatics of Insensitive Assessments. Understanding the Relativity of Assessments of Personal Taste, Epistemic Modals, and More', The Baltic International Yearbook of Cognition, Logic and Communication 6 (2011), pp. 1-45.

Blackburn, Simon. Ruling Passions. Oxford: Clarendon Press, 1998.

Bramble, Ben. 'Consequentialism about Meaning in Life', Utilitas 27:4 (2015), pp. 445-459.

Brogaard, Berit, and Barry Smith. 'On Luck, Responsibility and the Meaning of Life', Philosophical Papers 34:3 (2005), pp. 443-458.

Budd, Malcolm. 'The Acquaintance Principle', British Journal of Aesthetics 43:4 (2003), pp. 386-392.

Evers, Daan. 'Relativism and the Metaphysics of Value', unpublished.

Finlay, Stephen. 'The Error in the Error Theory', Australasian Journal of Philosophy 86:3 (2008), pp. 347-369.

Finlay, Stephen. Confusion of Tongues. A Theory of Normative Language. Oxford: Oxford University Press, 2014.

Frankfurt, Harry. 'Reply to Susan Wolf', in Contours of Agency: Essays on Themes from Harry Frankfurt, edited by Sarah Buss, and Lee Overton. Cambridge, MA: MIT Press, Bradford Books, 2002, pp. 245-252.

Gibbard, Allan. Thinking How to Live. Cambridge, MA: Harvard University Press, 2003.

Kauppinen, Anti. 'Meaningfulness and Time', Philosophy and Phenomenological Research 84:2 (2012), pp. 345-377.

Kant, Immanuel. Critique of Judgement. translated by James Meredith. Oxford: Clarendon Press, 1951.

Luper, Steven. 'Life's Meaning', in The Cambridge Companion to Life and Death, edited by Steven Luper. Cambridge: Cambridge University Press, 2014, pp. 198-214.

MacFarlane, John. Assessment Sensitivity. Relative Truth and Its Applications. Oxford: Oxford University Press, 2014.

Metz, Thaddeus. Meaning in Life. Oxford: Oxford University Press, 2013.

45 I would like to thank Frans Svensson for organizing and inviting me to a symposium on the meaning of life and objective values at the University of Umeå in November 2016. I would also like to thank him for helpful comments on the paper. The same goes for Thad Metz, Chris Woodard, Madeleine Hayenhjelm, two anonymous referees for De Ethica and the participants in the Grundlegung session at the University of Groningen, where a version of this paper was discussed. 
De Ethica. A Journal of Philosophical, Theological and Applied Ethics Vol. 4:3 (2017)

Nagel, Thomas. 'The Absurd', The Journal of Philosophy 68:20 (1971), pp. 716-727.

Ridge, Michael. Impassioned Belief. Oxford: Oxford University Press, 2014.

Rowlands, Mark. 'The Immortal, the Intrinsic, and the Quasi Meaning of Life', The Journal of Ethics 19:3/4 (2015), pp. 379-408.

Smart, John, and Bernard Williams. Utilitarianism: For and Against, Cambridge: Cambridge University Press, 1973.

Smuts, Aaron. 'The Good Cause Account of the Meaning of Life', The Southern Journal of Philosophy 51:4 (2013), pp. 536-562.

Street, Sharon. 'Constructivism about Reasons', in Oxford Studies in Metaethics vol. 3, edited by Russ Shafer-Landau. Oxford: Clarendon Press, 2008, pp. 207-245.

Taylor, Richard. 'The Meaning of Life', in The Meaning of Life: A Reader, $3^{\text {rd }}$ edition, edited by Elmer Klemke, and Stephen Cahn. New York: Oxford University Press, 2009, pp. 13-14.

Todd, Cain. 'Quasi-Realism, Acquaintance, and the Normative Claims of Aesthetic Judgement', British Journal of Aesthetics 44:3 (2004), pp. 277-296.

Williams, Bernard. 'Internal and External Reasons', in Moral Luck. Philosophical Papers 1973-1980. Cambridge: Cambridge University Press, 1981, pp. 101-113.

Wolf, Susan. Meaning in Life and Why it Matters. Princeton: Princeton University Press, 2010. 
De Ethica. A Journal of Philosophical, Theological and Applied Ethics Vol. 4:3 (2017) 